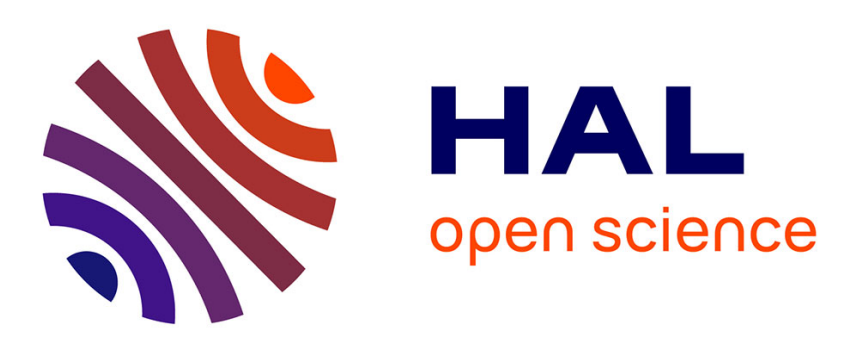

\title{
Analysis of Cecropia sciadophylla Morphogenesis Based on a Sink-Source Dynamic Model
}

Véronique Letort, Patrick Heuret, Paul Camilo Zalamea, Eric A. Nicolini, P. de Reffye

\section{- To cite this version:}

Véronique Letort, Patrick Heuret, Paul Camilo Zalamea, Eric A. Nicolini, P. de Reffye. Analysis of Cecropia sciadophylla Morphogenesis Based on a Sink-Source Dynamic Model. 2009 Plant Growth Modeling And Applications, Nov 2009, Beijing, China. pp.10-17. hal-00546782

HAL Id: hal-00546782

https://hal.science/hal-00546782

Submitted on 15 Dec 2010

HAL is a multi-disciplinary open access archive for the deposit and dissemination of scientific research documents, whether they are published or not. The documents may come from teaching and research institutions in France or abroad, or from public or private research centers.
L'archive ouverte pluridisciplinaire HAL, est destinée au dépôt et à la diffusion de documents scientifiques de niveau recherche, publiés ou non, émanant des établissements d'enseignement et de recherche français ou étrangers, des laboratoires publics ou privés. 


\title{
Analysis of Cecropia sciadophylla Morphogenesis Based on a Sink-Source Dynamic Model
}

\author{
Véronique Letort $^{* \dagger}$, Patrick Heuret ${ }^{\ddagger}$, Paul-Camilo Zalamea ${ }^{\S}$, Eric Nicolini ${ }^{\llbracket}$ and Philippe de Reffye $\mathrm{e}^{\dagger \uparrow}$ \\ *MAS, Ecole Centrale Paris, Chatenay-Malabry, F-92290 France \\ ${ }^{\dagger}$ INRIA Futurs, EPI Digiplante, Orsay, France \\ $\ddagger$ INRA, UMR AMAP, Montpellier, F-34000 France \\ $\S$ IRD, UMR AMAP, Montpellier, F-34000 France \\ ICIRAD, UMR AMAP, Montpellier, F-34000 France \\ "Universidad de los Andes, Departemento de Ciencias Biológicas, Bogotá, Colombia \\ E-mail of corresponding author : letort@mas.ecp.fr
}

\begin{abstract}
Although there is an increasing number of models simulating the functional and structural development of trees at organ scale, few of them can be fully calibrated, evaluated and validated. A major obstacle resides in the intrinsic complexity of trees due to their high stature, large number of organs and long life span that limits the possibilities of experimental work and the access to measurement data. This is why 'model plants' such as the neotropical genus Cecropia are of great interest. This genus has a simple architecture and some qualities that allow collecting exhaustive datasets at the organ scale. In this paper, we evaluate the GreenLab model on data recorded on 11 individuals measured in 2007 in French Guiana. The branching and flowering patterns are analyzed using an index of trophic competition.
\end{abstract}

\section{Introduction}

Trees are characterized by their high stature, by the complexity of their structure and by their long lifespan. These properties drastically increase the experimental work required for analysing trees as a whole. This intrinsic difficulty for collecting adequate data is a major obstacle for model development, parameterization and validation. This is particularly true when ones aims to considerer the growth processes at the organ scale and to account for interactions between plant functioning and structure [1], [2].

In that context, it is of great interest to consider 'model plants' to build and validate tree growth models. The neotropical genus Cecropia Loefl. includes 61 species, distributed from southern Mexico to northern Argentina, with some species occurring in the Antilles. It is the most important genus of pioneer trees in the neotropics; it grows rapidly and ably colonizes gaps [3]. Species of this genus present all the required characteristics for a 'model plant'. It has a continuous growth, immediate branching and flowering, a very simple architecture following the architectural model of Rauh with a pronounced candelabrum-like branching system [4] and associated to a low complexity for a relatively high lifespan (i.e., some decades). For example, an eleven-yearold measured individual of $C$. sciadophylla was constituted by approximately 1700 nodes and 400 leaves still alive that is relatively low compared to the majority of trees (see Figure 1). Furthermore, for Cecropia species, the rate of emission of new nodes is remarkably stable among the axes of a tree but also among the trees of a population [5], [6]; for example in Cecropia sciadophylla each axis increases by 25 phytomers per year. As the scar of leaves are identifiable during the whole tree life, it gives a temporal reference to retrospectively assess the tree age [6]. Moreover, these species exhibit strong periodic patterns for branching and flowering as well as for the variations of internode length. The origins of these periodic patterns is questionable: among others, can we involve climatic fluctuation or/and dynamic trophic competition during the plant development?

Such question could be investigated using a model that simulates biomass production and allocation in relation with the plant structure, such as for instance the GreenLab model [7]. Mathieu et al [8] have shown that cyclic flowering or branching patterns can be generated as emergent properties in the model. These cyclic patterns are driven by the sourcesink ratio that is calculated by GreenLab and that represents an index of internal trophic competition. A first attempt of parametric identification of the model on adult trees was performed by [9] on two beech trees but, while each metamer dimensions were measured on the trunk, on the branches only compartment data were collected. In contrast, a major advantage of Cecropia is that all phytomers of the trees can be exhaustively measured. Therefore, studying this genus offers for the first time (to our knowledge) the opportunity to evaluate the performances of a functionalstructural model using a complete dataset at the organ level.

In this study, we focus on $C$. sciadophylla that recently 
was the object of a detailed morphological and architectural study [6]. Its habitat covers the Amazonian basin, the Llanos region in Colombia and Venezuela, and the Guiana shield. With the objective to simulate the growth of Cecropia sciadophylla at an organ scale and to reproduce the biomass production and allocation at metamer level, the aims of this work are $(i)$ to determine morphological allometries to simplify future measurements, (ii) to evaluate the ability of the GreenLab model to trace back the dynamics of internal trophic competition within the plants and to reproduce their observed varibility, and (iii) to assess whether the index of trophic comptetition can be linked to the appareance of the first tier of branches and inflorescences.

\section{Material and Methods}

\subsection{Study site}

Two populations of Cecropia sciadophylla Mart. were studied in French Guiana. The first one was located at SaintElie road $\left(5^{\circ} 17^{\prime} \mathrm{N}, 53^{\circ} 04 \mathrm{~W}\right)$. The second one was located at ca. $20 \mathrm{~km}$ from Saint Elie road, on Counami road $\left(05^{\circ} 24\right.$ $\left.\mathrm{N}, 53^{\circ} 11 \mathrm{~W}\right)$. Climate in French Guiana is seasonal with a 3-months dry season from mid-August to mid-November and a rainy season during the other 9 months. Additionally, a short dry season may occur in February and March. Mean annual rainfall is $\approx 3000 \mathrm{~mm} / \mathrm{yr}$.

\subsection{Plant material and measurements}

In September 2007, 11 individuals were felled and measured, ten at Saint-Elie road and one at Counami Road. All the trees from Saint-Elie population were sterile and only one had branches. The tree from Counami road was pistillate and had branches. For all trees, trunk diameter at breast height $(1.30 \mathrm{~m})$ and tree height were measured on the fallen tree (Table 1).

Trees were described node by node as a collection of phytomers following the protocol defined in [5]. Tree topology, i.e. the relative position of the different botanical units described (nodes and axes), was recorded following the MTG formalism [10] and analysed using the VPlant package, the successor of AMAPmod [11] now integrated in the OpenAlea platform [12]. The age determination of trees and annual growth delimitation were performed following the protocol proposed by [6].

Each phytomer was indexed according to its ontogenetical age as defined by [13] and the following information was recorded: the length of the underlying internode, the diameter in the middle of the internode, and the presence of developed branches, inflorescences and/or leaves at each internode. Each leaf was cut and its petiole was separated from the blade. The blade was weighed and pressed between two plates of Plexiglas and then photographed using a digital camera with a focal length of $50 \mathrm{~mm}$. Blade areas were estimated by analysing the photographies with the ImageJ freeware (http://rsbweb.nih.gov/ij/). The length, the diameter in the middle and the fresh weight of the petioles were recorded. The fresh weight of inflorescence or infructescence were recorded. The plant axes were then cut node by node, $1 \mathrm{~cm}$ above the top of the stipule scar. The length of the cut segment (not exactly equal to the internode as there is a 1 $\mathrm{cm}$ shift) was recorded as well as its fresh weight and two orthogonal diameters of the pith. Node segments, leaves, and petioles were dried at $103^{\circ} \mathrm{C}$ during $72 \mathrm{~h}$ and the dry mass was measured. For young individuals (number of phytomers less than around 55), the root system was extracted, washed, dried and weighed.

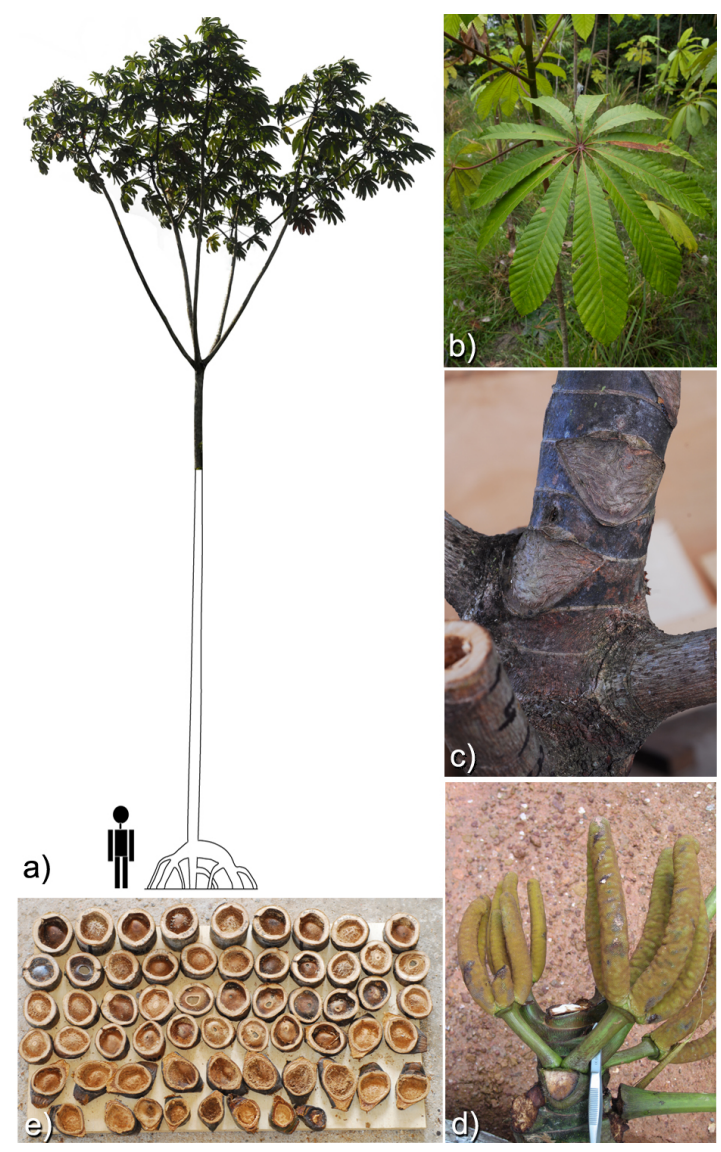

Figure 1. (a) Habit of Cecropia sciadophylla ; this individual is 11 year old with a height of $19.5 \mathrm{~m}$, a DBH of $12.5 \mathrm{~cm}$ and composed of 21 axes with a total of 1780 nodes and 381 leaves ; (b) detail of a compound leaf ; (c) detail of an axis at the point of insertion of lateral shoots ; (d) detail of a female inflorescence and (e) transversal cuts for each node of the terminal part of an axis. 


\subsection{Model and procedure for its parametric iden- tification}

The GreenLab model was used with some adaptations to perform the analysis of source-sink dynamics during Cecropia growth. GreenLab is a functional-structural model based on carbon source-sink relationships within individual plants that are represented as sets of topologically connected phytomers [7], [14], [15]. The model time step corresponds to the time lag between the emission of two successive phytomers, called growth cycle (GC). For Cecropia, all axes are assumed to have the same functioning and set of parameters. Two phases can be distinguished in axis development: a growth establishment phase (as defined in [13]) during which the allometric and sink relationships within organs vary, and a stable phase.

2.3.1. Biomass production. The initial biomass input in the system, $Q(0)$, corresponds to the dry mass of the first phytomer. It was estimated from data on dry mass of the last phytomers produced by the plants. Biomass production at GC $t, Q_{p}(t)$, is computed according to the available blade surface $S(t)$ as follows:

$$
Q_{p}(t)=\frac{E}{R} \cdot S(t)
$$

where $1 / R$ is a factor of biomass conversion efficiency and $E$ is a factor representing the local environmental conditions: it can be considered as a site-specific factor that regulates the potential biomass production (independent of time). Contrary to the precedent versions of the GreenLab model (e.g. [14]), no exponential term appears which would drive a saturation of biomass production due to self-shadowing and competition with neighbour trees. Indeed, for Cecropia, leaves are spatially organized at tips of axes so that selfshadowing is low; there is few overlapping. A similar observation of low self-shading was reported in [16] for Cecropia longipes.

2.3.2. Biomass allocation to the main growth compartments. The biomass produced is first allocated based on a model of sink competition at compartment level: roots, rings, new organs, and expansion of existing organs.

As no sufficient information was available on the dynamics of the root compartment, we assumed that a constant proportion of biomass is allocated to root growth. The resting aerial biomass, $Q(t)$ is partitioned to the aerial compartments proportionnally to their respective demands, the sum of which defines the total demand of the plant at GC $t, D(t)$.

The demand of new organs compartment $D^{b}(t)$ is the sum of the active meristem sinks of the plant. The demand $d^{b}(k)$ of a meristem (hereafter called bud) of rank $k$ varies linearly with $k$ to account for the ontogenetical variations during the establisment phase:

$$
d^{b}(k)=P^{b} \cdot \min \left(1, k \cdot V^{b}\right)
$$

where $P^{b}$ is the value of bud sink once the stable phase is reached. The slope of the variation, $V^{b}$, is a parameter of the model. The demand includes only the sinks of buds that will produce phytomers: resting or aborted lateral buds are not taken into account.

The demand of the expansion compartment $D^{e}(t)$ is defined as the sum of sinks of active organs within the plant. Demand of an organ for its expansion is defined as in [17] by a beta law density function normalized by its maximum value and multiplied by the organ sink value.

The demand of the ring compartment $D^{r}(t)$ is assumed to depend on the total active blade surface $S(t)$, in reference to the widely used pipe model theory [18]. As biomass allocated to ring increment is also known to depend on the environmental conditions and on the vigour state of the tree, a dependance to the supply to demand ratio $(Q / D(t))$ is also taken into account as follows:

$$
D^{r}(t)=P^{r} \cdot S(t) \cdot \frac{Q}{D}(t)
$$

$P^{r}$ is a parameter representing the sink strenght of the ring compartment. Note that due to the presence of this term, the total aerial plant demand $D(t)$ must be calculated as the solution of an order 2 polynomial equation.

Then biomass is allocated to each compartment: $Q^{c}(t)=$ $D^{c}(t) \cdot Q / D(t)$, where $c \in b, e, r$ stands for buds, expansion and rings respectively.

2.3.3. Biomass partitioning within compartments. The biomass allocated to the bud compartment, $Q^{b}$, is shared between all new phytomers for their primary growth proportionally to their demand $d^{b}(k)$ as defined above. Within each phytomer, a submodel of sink competition is run to compute the biomass allocated to each organ, as defined in [15], according to their respective sinks $P^{o}$.

Biomass for expansion $Q^{e}(t)$ is partitioned between all expanding organs according to their age and to the shape of their sink variation, as classically done (e.g. [17]).

The biomass of the ring compartment, $Q^{r}$, is spread along the tree axes to add a new layer to every internode. The ring growth of each phytomer depends on their length and on the functinal blade surface above them in the tree architecture:

$$
q_{k}^{r}\left(b_{o}, t\right)=Q^{r} \cdot l_{k}\left(b_{o}, t\right) \cdot S_{k}^{a}\left(b_{o}, t\right) / d^{r}(t)
$$

where $l_{k}\left(b_{o}, t\right)$ is the length of the phytomer considered, indexed by its rank $k$, its branching order $b_{o}$ and the current GC $t$. $S_{k}^{a}\left(b_{o}, t\right)$ is the active blade surface located above it. $d^{r}(t)$ is the secondary demand for ring partitioning from the 
ring pool of biomass. It is calculated as:

$$
d^{r}(t)=\sum_{k=1}^{t} \sum_{b_{o}=1}^{\max b_{o}} l_{k}\left(b_{o}, t\right) \cdot S_{k}^{a}\left(b_{o}, t\right)
$$

where $\max b_{o}$ is the maximal branching order.

2.3.4. Variable allometries. As the pith is hollow, internodes of Cecropia have shapes of hollow cylinders. To simplify the computation of geometrical shapes and to reduce the number of parameters, we considered that the organ shape is equivalent to the full cylinder that has the same volume as the hollow one. This volume $v\left(k, t, b_{o}\right)$ is computed from the amount of dry mass allocated to the internode. The dry mass to volume ratio depends on the distance of the phytomer to the apex: an allometric relationship was establised from observed data (see section 3 ). The internode length $l$ is deduced from its volume $v$ by the classical allometry:

$$
l\left(k, t, b_{o}\right)=\sqrt{B e_{k}} \cdot\left(v\left(k, t, b_{o}\right)\right) \frac{1+\beta_{k}}{2}
$$

$B e_{k}$ and $\beta_{k}$ vary with phytomer rank $k$ during the establishment phase and then stabilize.

Blade area is computed from blade dry mass using the specific blade mass (SBM) factor, which is the ratio of blade dry mass $(\mathrm{g})$ to blade fresh area $\left(\mathrm{cm}^{2}\right)$. As SBM values may change with plant age [16] or when the light environment of the plant changes (e.g. at emergence from the surrouding vegetation), it was chosen to link SBM to the ratio of biomass supply to demand (Q/D) that should be a good indicator of the plant current state. To account for the stabilization of SBM, a maximal value $\left(S B M_{\max }\right)$ was estimated from the data for each individual. Thus the SBM value of individual $i$ at time $t$ was calculated as follows:

$S B M(i, t)=\min \left\{S B M_{\max }(i), S B M_{\min }+V^{S} \cdot \frac{Q}{D}(i, t)\right\}$

where $S B M_{\min }$ is the minimal value of SBM observed for our youngest individuals and $V^{S}$ is a parameter of the model.

2.3.5. Target data and parameter estimation. For each tree, the target data consisted in a topological description (phytomers and axes positions) and for each phytomer in its internode dry mass, internode (fresh) length, internode (fresh) diameter, blade dry mass, blade (fresh) area, petiole dry mass and infructescence dry mass. Specific allometries were estimated from the data to link organ dry mass to their fresh dimensions (e.g. SBM was computed from the ratios of blade dry weight to blade area).

As our goal in this study was to reproduce the growth of several individuals in order to extract the variations of their source-sink ratio over time, the topology was set

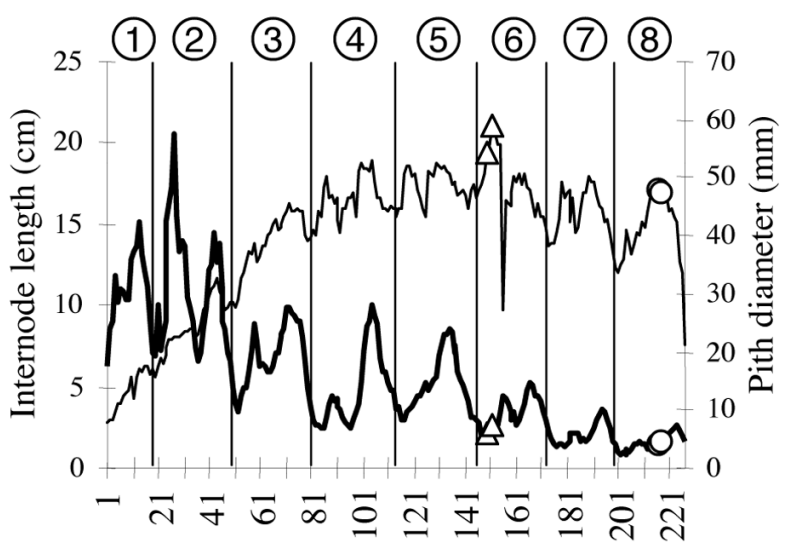

Internode rank from the base of the trunk

Figure 2. Age determination. Internodes length (bold black line) and pith diameter (line) of phytomers along the main stem of tree 10 and localization of branches (open triangles) and inflorescences (open circles).

directly as read in target files. Although the individuals were growing in different environments and despite the variability observed among their characteristics, we tested whether they could be considered as several realizations of the same theoretical individual. Therefore, 11 individuals were fitted in parallel, simulating their growth using a single set of parameters (multi-fitting [14]), except for three parameters that were considered as individual-specific: a local environmental factor, maximal blade thickness and leaf lifespan. The parameter estimation was performed using the generalized non linear least squares implemented in the Digiplante software [7].

\section{Results}

\subsection{Data analysis and parameter inputs}

The period between the emission of two successive phytomers is approximatively two weeks. The age of the measured individuals was determined using (i) the periodic variations of internode lengths and pith diameters and (ii) the positions of branches and inflorescences (Figure 2). Results are presented in table 1 along with other main characteristics classically used to describe trees (e.g. diameter at breast height, height, aerial biomass). It illustrates the high variability of the individuals measured: for instance, the fresh mass of tree 9 was similar to that of tree 8 , although the latter was 5 years older than the former. Tree 8 was older than tree 10 but it had only one branch while tree 10 had two branches of second order and one branch of third order. Besides, only tree 10 had infructescences.

A good linear correlation was found between blade area and blade dry mass $\left(a=56.3 m+186.6, \mathrm{R}^{2}=0.91, \mathrm{n}=523\right)$ 
Table 1. Characteristics of measured individuals.

\begin{tabular}{c|cccccc} 
ID & Age & Nphyt. & Loc. & H $(\mathrm{m})$ & DBH $(\mathrm{cm})$ & AerMass $(\mathrm{g})$ \\
\hline 1 & 2 & 55 & $\mathrm{E}$ & 3.61 & 3.9 & 5481 \\
2 & 2 & 55 & $\mathrm{E}$ & 2.97 & 2.3 & 1092 \\
3 & 2 & 45 & $\mathrm{E}$ & 2.2 & 1.2 & 341 \\
4 & 1 & 18 & $\mathrm{E}$ & 0.35 & - & 38 \\
5 & 1 & 29 & $\mathrm{E}$ & 0.08 & - & 2 \\
6 & 2 & 33 & $\mathrm{E}$ & 0.71 & - & 70 \\
7 & 2 & 37 & $\mathrm{E}$ & 0.77 & - & 125 \\
8 & 8 & 248 & $\mathrm{E}$ & 9.87 & 9.3 & 40720 \\
9 & 3 & 74 & $\mathrm{E}$ & 7.72 & 9.5 & 40605 \\
10 & 8 & 391 & $\mathrm{C}$ & 12.64 & 13.4 & 71741 \\
11 & 2 & 52 & $\mathrm{E}$ & 1.49 & 1.6 & 486 \\
\hline \multicolumn{7}{c}{ ID: identifier index, Age: ontogenetical age (years), } \\
Loc. : location (E:Saint-Elie, C: Counami), H: height (m),
\end{tabular}

DBH: diameter at breast height $(\mathrm{cm})$, AerMass: total aerial fresh mass $(\mathrm{g})$.

and petiole fresh diameter $\left(a=35.3 d-14.1, \mathrm{R}^{2}=0.92\right.$, $\mathrm{n}=523$ ). The specific blade mass estimated for each tree as the mean ratio of blade dry mass to blade area can be found in Table 2. Root dry mass was measured for the eight youngest individuals. The ratio between root mass and total mass was found equal to 0.19 in average (SD 0.059).

An assumption in the model is that all axes of Cecropia share the same parameter values. For the two branched trees (8 and 10), organ weights were similar regardless of the branching order (see figure 3). At the axis emergence, there is a phase of growth establishment during which the phytomer characteristics vary. Younger branches have phytomers with lower mass (five times lower in average) and within phytomers, the partitioning of biomass favors more the internodes than in older branches (Figure 3). The ratio between petiole dry mass and blade dry mass was found relatively stable with a mean value of $0.27(\mathrm{SD}=0.089$, $\mathrm{n}=587$ ). In contrast, the proportion of internode mass within a phytomer decreases with phytomer mass and hence the internode sink was linked by an allometric relatioship to the phytomer meristem dry mass: $P^{i}=0.466 *\left(q^{b}\right)^{0.27}, R^{2}=$ $0.21, n=563$ (data not shnown). The ratio between internode dry mass and its volume was found relatively constant except for the young phytomers. This can be due to the fact that maturating internodes have a different wood density value. In the simulation, this ratio was set dependent on the phytomer distance to apex, $d$, as follows: $m / v(d)=0.24 \cdot d^{0.12}, R^{2}=0.15$. The allometric coefficient $\beta$ defining internode dimensions (length and section area) was set to 0.9 , since the internodal length is highly variable. The coefficient $\beta$ was varied during the establishment phase following a beta-shape function fitted with the model.

3.1.1. Fitting results. The 11 measured individuals were fitted in parallel with data of their organ dimensions and mass, representing a total of more than 4600 data points. Table 2 gathers the parameter values estimated from the data or fitted through the model by global optimization (18
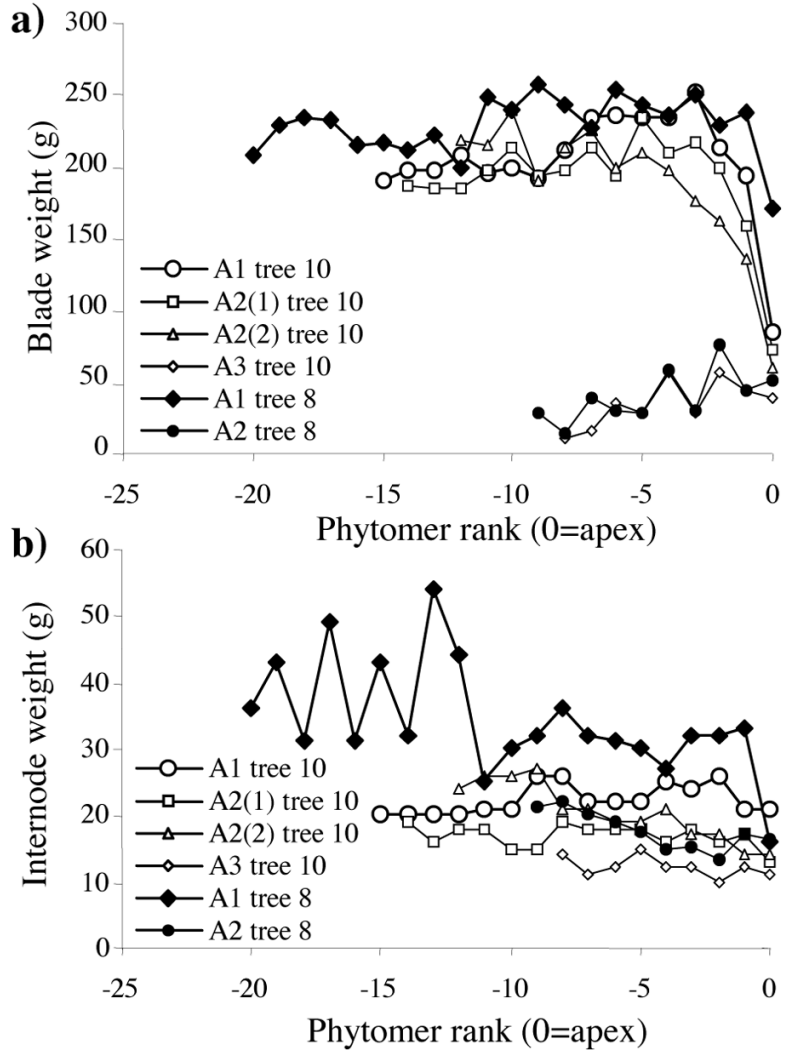

Figure 3. Internode and blade fresh mass on tips of branches for trees 8 and 10. A1: trunk, A2: branch order 2, A3: branch order 3 .

fitted parameters). For each plant, a value of site-specific local environment is fitted. As the parameter of resistivity to biomass production, $R$, is also fitted, the two parameters $E$ and $R$ are not identifiable together. A reference value has to be chosen for at least one tree, otherwise there would be an inifinite number of possible solutions. The reference value is arbitrarily set to 10 , for tree 10 . Values of the environmental factor for the remaining trees are estimated relatively to this reference tree and the results are consistent with qualitative observations of the tree local environments. The adjusted coefficients of determination $\left(R^{2}\right)$ are 0.65 , $0.18,0.54,0.75,0.75,0.75,0.56$ for internode mass, length, diameter, blade area, mass and petiole mass respectively. The coefficient of determination for compartment data are all above 0.98. Figure 4 shows some of the graph outputs: simulated and observed internode and blade mass along the trunk according to phytomer rank (a-c); variations of simulated internode and blade biomass of the whole plants from emergence to the date of our destructive measurement (observed values represented as dots) (b-d). Figure 5 shows the evolution of the ratio of biomass supply to demand over time for the 11 fitted trees. Branch appearance induces a 


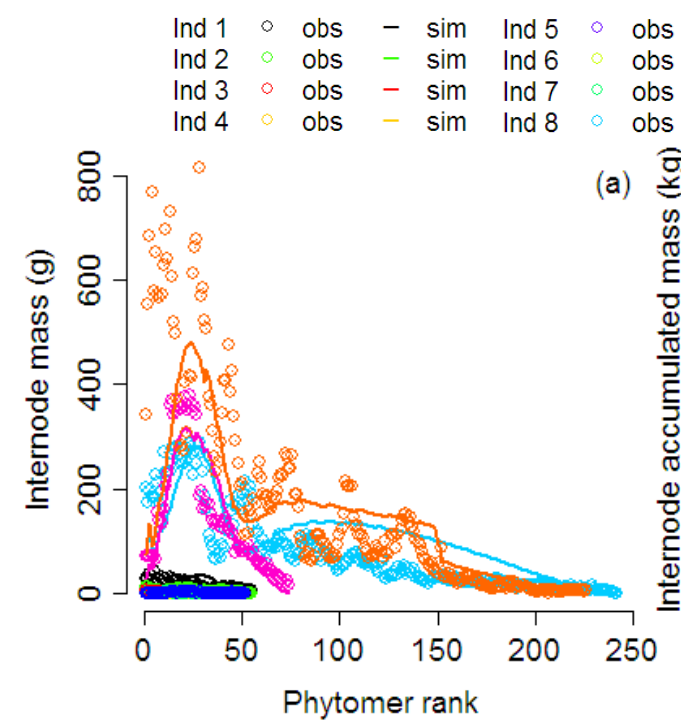

obs $-\operatorname{sim}$ Ind $9 \circ$ obs $-\operatorname{sim}$
obs $-\operatorname{sim}$ Ind $10 \circ$
obs $-\operatorname{sim}$ Ind $11 \circ$ obs $-\operatorname{sim}$
obs $-\operatorname{sim}$
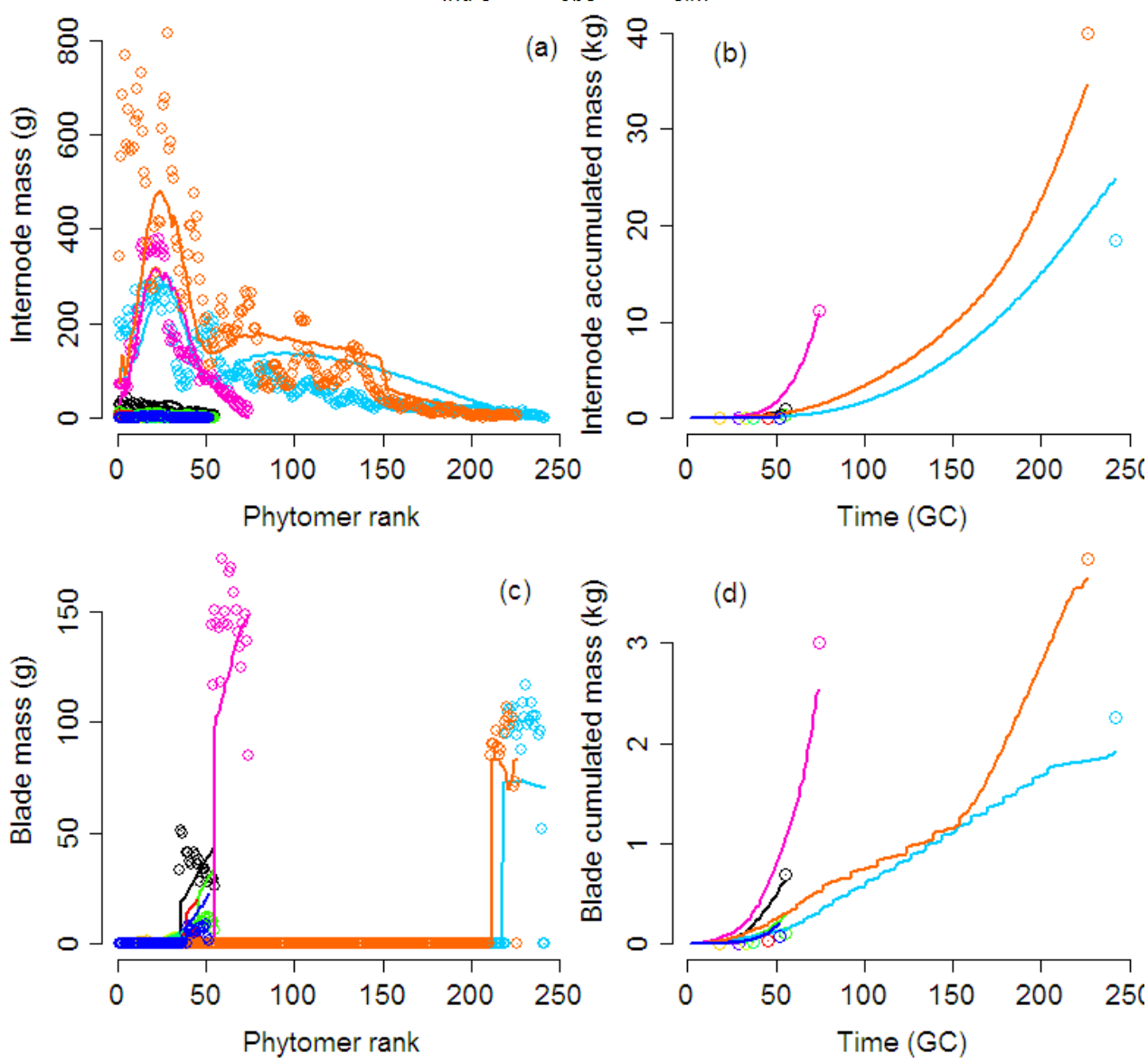

Figure 4. Fitting results for the 11 individuals: internode(a) and blade (b) phytomer mass vs. rank along the main stem, internode (b) and blade (d) accumulated mass vs. time

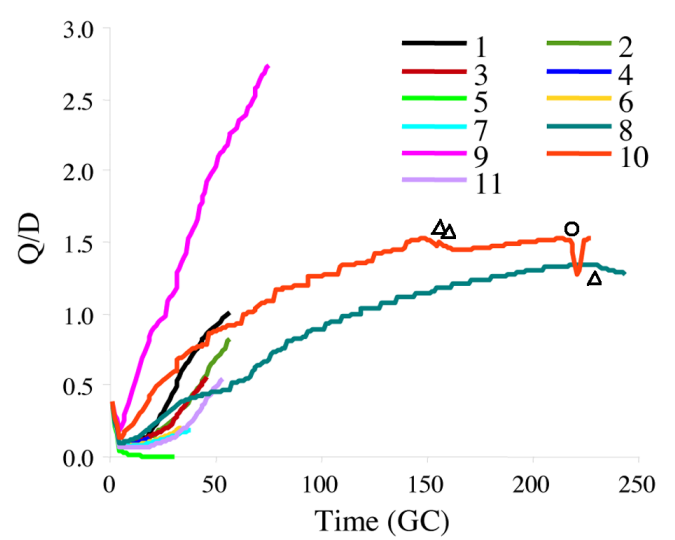

Figure 5. Variations of the source-sink ratio $(Q / D)$ with time for the 11 fitted individuals, with appearance dates of branches (open triangles) and fruits (open circles). decrease in this ratio as it increases the demand. This effect is not pronounced for two main reasons: (i) the phytomer bud sink is small at branch emergence and (ii) branch emergence also increases the plant photosynthetical sources. In contrast, the appearance of fruits has a strong impact on the sourcesink ratio but this influence is limited to the duration of fruit expansion. One of our objectives was to investigate the existence of a relationship between the state of trophic competition within the plant (represented by the source-sink ratio) and the rhythms of branching and flowering. In that context, our results showed that the source-sink ratio might be a driving variable of branch and fruit emergence but has to be coupled with other factors as tree 9 has no branches although it exhibits the highest values of sink-source ratio (see Figure 5). 
Table 2. Estimated parameters diretcly from data or by using global model calibration (marked with asterisk).

\begin{tabular}{|c|c|c|}
\hline & \multicolumn{2}{|c|}{ Tree-specific parameters (Tree 1 to 11) } \\
\hline$S B M_{\max }$ & \\
\hline & \multirow{2}{*}{\multicolumn{2}{|c|}{$\begin{array}{l}0.012 ; 0.0091 ; 0.0086 ; 0.0075 ; 0.0080 \\
0.0079 ; 0.0089 ; 0.017 ; 0.015 ; 0.017 ; 0.012\end{array}$}} \\
\hline & & \\
\hline$T_{f}$ & \multicolumn{2}{|c|}{ Maximal number of active leaves } \\
\hline & \multicolumn{2}{|l|}{$21 ; 10 ; 7 ; 7 ; 6 ; 6 ; 7 ; 21 ; 22 ; 16 ; 15$} \\
\hline$E_{i}$ & \multicolumn{2}{|l|}{ Environment factor* } \\
\hline & \multicolumn{2}{|c|}{$\begin{array}{l}6.77 ; 7.12 ; 7.15 ; 6.02 ; 3.17 \\
6.43 ; 6.52 ; 7.39 ; 13.47 ; 10 \text { (reference); } 6.09\end{array}$} \\
\hline \multicolumn{3}{|c|}{ Parameters common to all trees } \\
\hline$Q_{0}$ & Initial biomass & $1.5 \mathrm{~g}$ \\
\hline$x_{r}$ & Biomass proportion to roots & $19 \%$ \\
\hline$R$ & Inverse of conversion efficiency* & 1322 \\
\hline$P^{a}$ & Blade sink (ref) & 1 \\
\hline$P^{p}$ & Petiole sink & 0.27 \\
\hline$P^{f}$ & Fruit sink & 13.49 \\
\hline $\operatorname{Exp}^{f}$ & Fruit expansion duration & $T_{e}=6$ \\
\hline & Fruit expansion parameters & $a=4, b=1.5$ \\
\hline$P^{i}(k, t)$ & Internode sink: & $x=0.46$ \\
\hline & $x \cdot\left(q_{k}^{b}(t)\right)^{y}$ & $y=0.32$ \\
\hline$P^{b}$ & Bud sink, maximal value* & 69.8 \\
\hline$V^{b}$ & Bud sink, slope* with rank $\mathrm{k}$ & 0.015 \\
\hline$P^{r}$ & Ring sink* & 14.91 \\
\hline$S B M_{m i n}$ & SBM variation, minimum & $0.00749 \mathrm{~g} . \mathrm{cm}^{-2}$ \\
\hline$V^{S}$ & SBM variation, slope* with $\mathrm{Q} / \mathrm{D}$ & $0.0074 \mathrm{~cm}^{-2}$ \\
\hline$B e$ & Internode allometry factor* & ini $=1313$, end $=3.87$ \\
\hline$\beta$ & Internode allometry exponent & 0.9 \\
\hline$m / v(d)$ & In. dry mass to volume ratio: & $x=0.238$ \\
\hline
\end{tabular}

\section{Discussion and Conclusion}

For the first time, it was possible to analyse tree growth with the GreenLab model using a complete set of data. A first interesting result was the strong linear correlation found between fresh petiole diameter and blade area, which may considerably simplify the future experimental work. This study aimed to simulate all individuals with a single set of parameters and to reproduce the observed biomass varibility by using a single factor of environmental control. It allows to verify that the model structure is robust enough to simulate the growth of individuals at different ages and grown in different conditions. Indeed, when biomass data are considered, destructive measurements are required: data are collected on the tree at a fixed date and there is no data about their past growth, although the data collected result from the integration of long-term processes. This highlights the importance of multi-fitting (i.e. simultaneous fitting on several individuals at different growth stages) to evaluate the model, as well as for crops [14].

Although the core of GreenLab principles have been conserved, some equations of the model have been slightly modified to take into account the specificities of Cecropia, that mixes characteristics of both herbs and trees. In particular, it has been observed that when a new axis is emitted (including the main stem), there is a phase of growth establishment during which internode allometries vary (longer and thinner internodes) while the partitioning of biomass within the phytomer changes (more biomass is allocated to internode) and while pith diameter increases linearly (Figure 2). Here, the slope is presumably related to environmental conditions: a quick increase was observed for individuals growing in favorable environment. Most of these characteristics might be related to the meristem size whose diameter is smaller at branch emergence.

The fitting results highlighted some weak points of the model. As sinks are relative in GreenLab, the increase of organs with high demand, such as fruits, mechanistically induces a decrease of the size of the other organs. This effect is not observed on the measured individuals, even on the phytomers bearing fruits; it implies that other modelling choices should be considered for biomass allocation. For instance, Dingkuhn et al. discuss the possiblity that plant growth would be driven by sink regulation rather than by sources as classically done in allocation models [19]. Biomass allocation to the roots was coarsely simulated by allocating a constant proportion of the biomass production at each GC. This hypothesis is reasonable with regard to the data on young inidividuals but further investigation would be needed on older trees to get a more accurate model of root growth dynamics, in particular to take into account the growth of stilt-roots, that might be related to mechanical stability of the tree. The duration of leaf activity was set as a model input and estimated from observations. However, a more mechanistic modelling would be needed. It could be based on the theory of cost-benefit [20].

Previous studies on Cecropia have shown that internodal length have sinusoidal variations that could be related to the seasonal variations of rainfall [5], [6]. This pattern was also observed in our study but, to simplify our exploratory analysis, only a constant environment factor was considered for each tree. Further works must take into account these seasonal variations. It requires defining methods to detect accurately the number of phytomers emitted each year as the growth rates can slightly fluctuate.

Despite these limitations, the fitting procedure gives an insight in the plant internal trophic competition. The appearance of infructescences and branches induces a decrease in the supply to demand ratio. At emergence, new branches are more sinks than sources. This could be a first reason to explain the observed periodic branching patterns, although trophic competition is certainly not the only influent factor (for instance, tree 9 had a high sink-source ratio but had no branches). Further studies on individuals with more branches should help unraveling the effects of genetic control, seasonal environmental variations and internal trophic competition. 


\section{Acknowledgment}

The authors thank the students who helped us for the measurements during the training programm FTH organized by AgroParisTech, Kourou (UMR Ecofog): V. Bellassin, S. Braun, O. Djiwa, V. Le Tellier (FTH2007), L. Menard, A. Jaecque, K. Amine, J. Kaushalendra (FTH2008). We also thank B. Leudet, J. Beauchêne and F. Boyer for their help on the field, P.-H. Cournède for the use of the Digiplante software (Ecole Centrale Paris, EPI Digiplante) and C. Sarmiento for her valuable comments on our manuscript.

\section{References}

[1] R. Sievänen, E. Nikinmaa, P. Nygren, H. Ozier-Lafontaine, J. Perttunen, and H. Hakula, "Components of a functionalstructural tree model," Annals of Forest Sciences, vol. 57, pp. 399-412, 2000.

[2] P. Prusinkiewicz, "Modelling plant growth and development," Current Opinion in Plant Biology, vol. 7, no. 1, pp. 79-84, 2004.

[3] C. C. Berg and P. Franco Rosselli, Cecropia. New York Botanical Garden Press, New York, USA, 2005.

[4] F. Hallé, R. Oldeman, and P. Tomlinson, Tropical trees and forests, An architectural analysis. Springer-Verlag, NewYork, 1978.

[5] P. Heuret, D. Barthélémy, Y. Guédon, X. Coulmier, and J. Tancre, "Synchronization of growth, branching and flowering processes in the south american tropical tree Cecropia obtusa (Cecropiaceae)," American Journal of Botany, vol. 89, no. 7, pp. 1180-1187, 2002.

[6] P. Zalamea, P. Stevenson, S. Madrinán, P.-M. Aubert, and P. Heuret, "Growth pattern and age determination for Cecropia sciadophylla (Urticaceae)," American Journal of Botany, vol. 95, pp. 263-271, 2008.

[7] P. Cournède, M. Kang, A. Mathieu, J. Barczi, H. Yan, B. Hu, and P. de Reffye, "Structural factorization of plants to compute their functional and architectural growth," Simulation, vol. 82, no. 7, pp. 427-438, 2006.

[8] A. Mathieu, P.-H. Cournède, D. Barthélémy, and P. de Reffye, "Rhythms and alternating patterns in plants as emergent properties of a model of interaction between development and functioning," Annals of Botany, vol. 101, no. 8, pp. 1233$1242,2008$.

[9] V. Letort, P.-H. Cournède, A. Mathieu, P. de Reffye, and T. Constant, "Parameter identification of a functionalstructural tree growth model and application to beech trees (Fagus sylvatica)," Functional Plant Biology, vol. 35, pp. 951-963, 2008.

[10] C. Godin and Y. Caraglio, "A multiscale model of plant topological structures," Journal of Theoretical Biology, vol. 191, pp. 1-46, 1998 .
[11] C. Godin, E. Costes, and Y. Caraglio, "Exploring plant topological structure with the amapmod software: an outline," Silva Fennica, vol. 31, pp. 355-366, 31997.

[12] C. Pradal, F. Boudon, C. Nouguier, J. Chopard, and C. Godin, "PlantGL : A python-based geometric library for 3d plant modelling at different scales," Graphical Models, vol. 71, pp. $1-21,2009$.

[13] D. Barthélémy and Y. Caraglio, "Plant architecture: a dynamic, multilevel and comprehensive approach to plant form, structure and ontogeny," Annals of Botany, vol. 99, no. 3, pp. 375-407, 2007.

[14] Y. Guo, Y. Ma, Z. Zhan, B. Li, M. Dingkuhn, D. Luquet, and P. de Reffye, "Parameter optimization and field validation of the functional-structural model GreenLab for maize," Annals of Botany, vol. 97, pp. 217-230, 2006.

[15] A. Mathieu, P.-H. Cournède, V. Letort, D. Barthelemy, and P. de Reffye, "A dynamic model of plant growth with interactions between development and functional mechanisms to study plant structural plasticity related to trophic competition," Annals of Botany, vol. 103, pp. 1173-1186, 32009.

[16] K. Kitajima, S. Mulkey, M. Samaniego, and J. Wright, "Decline of photosynthetic capacity with leaf age and position in two tropical pioneer species," American Journal of Bontany, vol. 89, no. 12, pp. 1925-1932, 2002.

[17] A. Christophe, V. Letort, I. Hummel, P.-H. Cournède, P. De Reffye, and J. Lecoeur, "Model-based analysis of the dynamics of trophic competition during Arabidopsis thaliana development," Functional Plant Biology, vol. In Press., 2008.

[18] K. Shinozaki, K. Yoda, K. Hozumi, and T. Kira, "A quantitative analysis of plant form - the pipe model theory i. basic analysis," Japonese Journal of Ecology., vol. 14, pp. 97-105, 1964.

[19] M. Dingkuhn, D. Luquet, A. Clément-Vidal, L. Tambour, H. Kim, and Y. Song, "Is plant growth driven by sink regulation? implications for crop models, phenotyping approaches and ideotypes," in Proceedings of the Frontis workshop on Functional-Structural plant modelling in crop production, J. Spiertz, P. Struick, and H. Laar, Eds. Wageningen University and Research center, 2006.

[20] M.-L. Navas, B. Ducout, C. Roumet, J. Richarte, J. Garnier, and E. Garnier, "Leaf life span, dynamics and construction cost of species from mediterranean old-fields differing in successional status," New Phytologist, vol. 159, pp. 213-228, 2003. 